\title{
El poder de la solidaridad con Chile. La izquierda británica frente al golpe de Estado, 1973-1979*
}

\author{
The Power of Solidarity with Chile. \\ The British Left in Response to the Coup, \\ 1973-1979
}

\author{
Mariana Perry \\ (D) https://orcid.org/0000-0003-3220-5644 \\ Instituto de Historia \\ Facultad de Derecho y Gobierno \\ Universidad San Sebastián, Chile \\ mariana.perry@uss.cl
}

Resumen: El artículo busca primeramente identificar cuáles fueron las lecciones que las distintas versiones de la izquierda británica extrajeron del fin de la Unidad Popular y la consecuente instalación del régimen militar en Chile, en circunstancias de un gobierno liderado por el Partido Laborista. Asimismo, busca arrojar luz sobre cómo la actividad británica de solidaridad con la causa chilena permitió unir y dar sentido colectivo a esta dividida y a veces contrapuesta izquierda, representando un caso excepcional en el escenario de Europa occidental. Para ello se revisaron las colecciones de Judith Hart y la Chilean Solidarity Campaign en el Labour History Archive, en Manchester, y documentos del Foreign Office en el Archivo Nacional Británico. Se com-

* Este proyecto fue financiado por la Agencia Nacional de Investigación y desarrollo (ANID)/POSTDOCTORADO/3180014.

Cómo citaR: Perry, M. (2020). El poder de la solidaridad con Chile. La izquierda británica frente al golpe de Estado, 1973-1979. Secuencia (108), e1823. DoI: https://doi.org/10.18234/secuencia.v0i108.1823

c) Esta obra está protegida bajo una Licencia Creative Commons Atribución-NoComercial 4.0 Internacional. 
plementó lo anterior con bibliografía secundaria y entrevistas a informantes claves.

Palabras clave: Chile; golpe de Estado; izquierda británica; campañas de solidaridad; derechos humanos.

Abstract: The article first seeks to identify the lessons different versions of the British left drew from the end of Popular Unity and the subsequent installation of the military regime in Chile, under a government led by the Labor Party. Likewise, it attempts to shed light on how British solidarity with the Chilean cause made it possible to unite and give collective meaning to this divided left, sometimes plagued by infighting, representing an exceptional case in the Western European scenario. To this end, the collections of Judith Hart and the Chilean Solidarity Campaign in the Labor History Archive, in Manchester, and the Foreign Office documents in the British National Archives were reviewed. This was complemented by secondary bibliography and interviews with key informants.

Key words: Chile; coup; British left; solidarity campaigns; human rights.

Recibido: 4 de febrero de 2020 Aceptado: 21 de mayo de 2020

Publicado: 18 de diciembre de 2020

\section{INTRODUCCIÓN}

$\mathrm{C}^{1}$ experimento socialista de la Unidad Popular (UP) en Chile causó un Eimportante impacto en la política global. En un período en que la izquierda en Occidente experimentaba un renovado impulso, la "vía chilena al socialismo" contenida en su programa de gobierno, se posicionaba como un interesante experimento que ponía a prueba las posibilidades del sistema democrático liberal para avanzar hacia el socialismo. Si la revolución de Cuba había marcado la agenda de la nueva izquierda en los 1960, el proyecto de la up cumplió la función de renovar el debate de los partidos de izquierda tra- 
dicional al buscar articular el debate teórico y práctico sobre las posibilidades de la diada socialismo y democracia en la década de 1970.

La utilización del caso chileno para hablar de problemáticas locales se potenció con la vinculación que se hacía con el sistema político del país. Hasta 1973, Chile cultivaba una imagen de democracia estable, con un sistema de partidos de raigambre europea que permitía construir asociaciones directas con la realidad del viejo continente, reforzando la narrativa de que lo sucedido en Chile podía pasar en Europa. En paralelo, la derecha europea también evaluó con preocupación el caso, especialmente a la luz del renovado impulso que la izquierda estaba teniendo hacia finales de los años setenta del siglo xx. Este impacto en la política europea se enmarca en lo planteado por Marchesi (2018), quien resalta que muchos de los eventos locales del Cono Sur, que desempeñaron un tremendo papel en moldear la generación latinoamericana de los años sesenta, también impactaron los eventos globales de esa década y sus postrimerías.

La atención hacia los sucesos en Chile se vio fortalecida por la llegada de una comunidad de refugiados chilenos políticamente organizados. La simpatía que la vía chilena al socialismo de Allende había despertado en la izquierda europea, unido a la crudeza de la represión militar informada por los exiliados, contribuyeron para que el caso chileno adquiriera una importancia global pocas veces antes vista. El carácter simbólico que cobró el quiebre del proyecto allendista superó a las filas de izquierda y convocó también a quienes condenaron las transgresiones a la democracia en Chile y la violación a los derechos humanos, generando apoyos transversales.

Las evaluaciones de lo sucedió en Chile no se hicieron esperar y sirvieron para dar forma a los debates que inundaron a la izquierda europea (Ange11, 1996; 2013), especialmente, aquellos que se desarrollaron en torno al dilema sobre las vías posibles para alcanzar el socialismo, el cual dividía a las distintas versiones de la izquierda. La experiencia de up interpeló, por un lado, a la llamada vieja izquierda, al proponer asociaciones entre comunistas y socialistas en un conglomerado político que invitaba a construir la revolución desde las instituciones "democráticas burguesas", a través de una vía pacífica hacia el socialismo. Por otro lado, la nueva izquierda europea confirmaba su discurso sobre la necesidad de desmarcarse del aparato burocrático existente y barajar otras vías para alcanzar el socialismo. Además, la lección del fin de la up, para esta izquierda radicalizada o "nueva", era corroborar que la alianza entre comunismo y social democracia, perseguida por varias fuerzas en la 
izquierda occidental, era una falsa estrategia de revolución servil sólo para los intereses del imperialismo y el capitalismo (Christiaens, 2018, p. 418).

Sin embargo, al tiempo que la vía chilena al socialismo y su fracaso ahondaban las diferencias en las estrategias de las izquierdas europeas, las campañas de solidaridad con Chile convocaban a una audiencia extensa, a través de la identificación con ideales abstractos como revolución, socialismo y democracia, habilitando la acción colectiva sobre la base del activismo en defensa de los derechos humanos. El golpe de Estado en Chile y el duro régimen que lo procedió, se encontró con una estructura internacional orientada a la protección y defensa de los derechos humanos que permitieron canalizar el activismo transnacional, siendo el caso chileno el que logró cambiar las dinámicas de solidaridad hacia el tercer mundo (Green, 2003).

La recepción política inglesa del caso chileno permite el estudio de este fenómeno. La existencia de distintas versiones de la izquierda atentas a los desarrollos en Chile, junto con la organización y desarrollo de una campaña de solidaridad unida, permite analizar cómo los eventos en Chile generaron división por las lecciones extraídas y, al mismo tiempo, un acuerdo en torno a la necesidad de un activismo transnacional en contra del régimen militar, especialmente a la luz de la reivindicación de los derechos humanos como eje articulador. La unanimidad que convocó al activismo de la solidaridad británica con Chile se convierte en un caso interesante para analizar la modelación del discurso de la izquierda británica en general en un periodo de crisis del estado de bienestar y el avance hacia el modelo neoliberal, articulada en torno al discurso de los derechos humanos.

En el presente artículo se analizan las lecturas que la izquierda británica realizó del golpe de Estado en Chile para extraer las lecciones aplicables al contexto local, tal como sucedió en otros países europeos. De manera particular, se abordan las evaluaciones realizadas por el Partido Laborista (PL) que transitaba por un proceso de polarización política al momento del golpe en 1973 y que sólo un año después logró liderar el gobierno británico. En este caso se identifica cómo el caso chileno, y la coalición de la up, alentó las posturas presentes en el PL de trabajar hacia una mayor unidad en la izquierda para instaurar cambios orientados al socialismo al interior del sistema democrático. En este sentido, se encontraban con las lecciones extraídas por el comunismo británico, quienes, a propósito de la experiencia chilena, reafirmaban la política emanada desde Moscú, respecto a conciliar alianzas ampliadas con partidos burgueses para transitar por medios pacíficos hacia el socialismo. 
Se analizan también las interpretaciones realizadas por otras tendencias más radicales de la izquierda que, si bien tenían menor importancia electoral, cumplieron un rol en el debate político local e internacional. En este sentido, intelectuales de agrupaciones como International Marxist Group (IMG), The Socialist Register, o el Comité Internacional del Trotskismo británico utilizaron el caso chileno para demostrar la vacuidad de la vía democrática hacia el socialismo, confirmando la necesidad de avanzar hacia una vía revolucionaria en la consecución de la meta. Finalmente, se aborda la especificidad del caso británico respecto a la función que cumplió la campaña de solidaridad con Chile en unificar las altamente contrastantes posiciones entre la izquierda británica y articularlas bajo una idea más amplia de revolución internacional lideradas bajo un programa de solidaridad y defensa de los derechos humanos.

La resonancia del golpe chileno en la política mundial ha sido tratada en diversas obras en donde se destacan perspectivas generales como en Christiaens (2018) y Christiaens, Rodríguez García y Goddeeris (2014), y locales como en Camacho (2013), Santoni (2011), Perry (2016), entre otros. El caso específico del impacto del golpe entre las izquierdas británicas en conjunto con el tratamiento de las organizaciones de solidaridad no han sido lo suficientemente abordadas. Los textos existentes tratan desde perspectivas comparativas (Livingstone, 2018 y Jones, 2014), mientras que otros abordan específicamente las campañas de solidaridad (Bayle, 2012).

\section{EL VÍNCULO TRANSNACIONAL DE LA SOLIDARIDAD}

El éxito de la revolución en Cuba, la lucha en Vietnam y el caso chileno, sirvieron de inspiración y dieron sentido de unidad a jóvenes activistas a lo largo del mundo, quienes compartieron un sentimiento revolucionario que se desmarcaba de los contextos locales, forjándose lo que Suri (2003) llama un "lenguaje internacional del disenso" (p. 3). El común denominador era la idealización del concepto de revolución, que trascendía los ejemplos concretos y aunaba a activistas en Europa y Estados Unidos. Herederos de los sucesos de 1968 , los activistas comprometían su apoyo con todos los movimientos revolucionarios, particularmente aquellos del "tercer mundo", e intentaron aplicar los modelos a su propia realidad, fuesen estos contextos coloniales, economías occidentales basadas en el mercado o regímenes comunistas (Bracke, 2014; Eley, 2002). 
Una de las maneras en que se expresó este vínculo transnacional -principalmente entre las distintas versiones de izquierda- fue a través de campañas de solidaridad internacional, que combatían la sensación de statu quo que imponía la lógica de guerra fría (Christiaens, 2017). Las campañas servían, por un lado, para manifestar apoyo activo a ciertas causas y, por otro, para generar o direccionar debates locales. En referencia a las campañas organizadas en Norteamérica, pero aplicables a otros casos, Power y Charlip (2009) señalan que para los activistas el trabajo de solidaridad permitía la creación de un vínculo entre estadunidenses y latinoamericanos, debido a que perseguían los mismos objetivos y sostenían valores similares. En definitiva, las campañas de solidaridad política sirvieron para conectar ideas y personas en torno a temas generales o a un enemigo común, conformando la identidad de activistas revolucionarios aun perteneciendo a versiones distintas ( $y$ a veces contrapuestas) de la izquierda (Hatzky y Stites Mor, 2014).

Las campañas de solidaridad con la causa chilena se encumbraron rápidamente en un lugar central en la política de guerra fría. Para la izquierda radical europea, el derrocamiento de Allende se explicaba por el estancamiento causado por los excesivos acuerdos en el marco de la dètente, por lo que culpaban tanto al imperialismo soviético como al estadunidense por el golpe chileno. Para la izquierda occidental alojada en los partidos políticos tradicionales, la dureza de la represión a los simpatizantes de un gobierno socialista elegido democráticamente conectó la causa chilena con las reflexiones teóricas que buscaban crear referentes alejados del totalitarismo soviético. El comunismo soviético, por su parte, enmarcó la solidaridad chilena en una necesidad de incentivar la cooperación con occidente para combatir la percibida reemergencia del fascismo nivel mundial, evocando de este modo recuerdos de cooperación pasadas y proyectando espacios para mayor interacción con occidente (Christiaens, 2018).

Mientras las lecciones del caso chileno se utilizaban para definir estrategias políticas diversas al interior de la izquierda en occidente, la solidaridad con el destino de la causa democrática chilena permitía la confluencia de voluntades bajo el paraguas simbólico de defensa de los derechos humanos lo suficientemente amplio para convocar apoyos transversales. En otras palabras, el llamado a solidarizar con la causa democrática chilena lograba apelar a un amplio público, pues permitía la conexión directa entre activistas europeos y revolucionarios del tercer mundo, conformándose así una comunidad revolucionaria imaginada (Gildea, Mark y Pas, 2011). Además, ciertos 
aspectos de la historia chilena, tales como la intervención extranjera, el anticomunismo y la naturaleza de la coalición de la UP, permitían sobrepasar diferencias para reunirse en torno a un enemigo común simbolizado en el régimen de Augusto Pinochet.

En este contexto, la solidaridad con la causa chilena se instaló en un momento preciso que por sus características podía interpelar tanto a los activistas post 1968 europeo como a miembros de partidos políticos tradicionales. No obstante, la propuesta tras la "vía chilena al socialismo" al perfilarse como un segundo modelo (alternativo al socialismo soviético), generaba tanto expectativa como desconfianza por parte de las sensibilidades de izquierda presentes en el mapa europeo. Esto retrata un escenario de doble dimensión. Por un lado, el caso chileno era utilizado para dividir las aguas al interior de las izquierdas con respecto a temas como estrategias y alianzas para alcanzar determinados fines, a la vez que la solidaridad con el mismo caso permitía unificar voluntades en torno al discurso de defensa de los derechos humanos.

\section{LA IZQUIERDA BRITÁNICA}

El contexto político en la izquierda británica de los años setenta es un buen caso para analizar el fenómeno anterior. En 1974, el PL alcanzó mayoría para formar gobierno, con el programa más radical de su historia. Los movimientos sindicales habían emergido como fuerza determinante, llegando incluso a poner en jaque al gobierno conservador anterior liderado por Edward Heath; y distintos grupos de izquierda, menores en términos electorales pero visibles en términos mediáticos, formaban parte del espectro político de izquierda que sintió con gran fuerza los hechos chilenos.

Hacia la década de los sesenta, Inglaterra fue azotada por una profunda crisis económica que derivó en una crisis social y política cuyo símbolo se expresó en la necesidad de devaluar la libra esterlina, asumiendo de este modo el fin de un protagonismo mundial (Leys, 1989). Esta medida impactó negativamente en el empleo de los sectores industriales, agravando una crisis generalizada (Leys, 1989). Lo anterior significó una merma en el apoyo a los partidos políticos tradicionales y una pérdida de confianza en los valores socialdemócratas que habían sostenido el consenso de la década anterior. Además, los años sesenta estuvieron acompañados de una reactivación en 
la movilización política de los sindicatos, los que se perfilaron como actores políticos trascendentales en la década siguiente. En definitiva, el consenso de posguerra de un capitalismo benefactor hizo crisis a inicios de la década de los setenta, revelando una polarización en la sociedad inglesa entre intereses del capital y de los trabajadores.

Esta sensación de crisis, en donde la política del establishment había perdido autoridad, comenzó a poner en cuestión la capacidad de la democracia parlamentaria para mantener el orden político. Desde la elección de Edward Heath en 1970, el país había experimentado "el período más traumático de la historia política moderna" (Sandbrook, 2013, p. 125), con cinco estados de emergencia, dos huelgas mineras, paros industriales y la violencia desatada en Irlanda del norte. Aunque es posible sostener que la democracia nunca estuvo en real riesgo, la violencia percibida daba la sensación de una sociedad fracturada, marcada por la irreconciliable distancia entre aspiraciones de mayor movilidad social y la imposibilidad de la clase política, y el Estado en general, de cumplir con estos objetivos.

Escuchando a una base sindical polarizada, la Conferencia del PL de 1971 aprobó un programa de mayor radicalidad en vista a las próximas elecciones, incluyendo un "plan socialista de producción, basado en la propiedad pública, con una compensación mínima a los mandos superiores de la economía" (Leys, 1989, p. 94). De hecho, Tony Benn, líder de la izquierda al interior del laborismo, señaló que la crisis del sistema en 1970 le permitió al PL reencontrarse con su ideario socialista (Benn, 1981-1982).

En el escenario de desafección con la política tradicional, surgió una nueva izquierda británica (NIB) cuyo origen se identifica a partir de las renuncias al Partido Comunista Británico (PCGB) luego de la invasión soviética a Hungría en 1956 y su consolidación con la crisis del canal de Suez. Se posicionó en un tercer lugar entre el estalinismo y la social democracia, rechazando la bancarrota política y moral de ambos (Davis, 2009). Si bien la NIB tenía un origen eminentemente intelectual, asociado a editoriales, revistas y universidades, se nutrió del tipo de activismo que rodeó las campañas pro desarme nuclear y en las acciones directas de protesta civil del Comité de Acción Directa, lo que le permitió proyectar un internacionalismo que sobrepasaba el campo de acción de la guerra fría (Eley, 2002, pp. 355-356). Sin bien la NIB criticaba la estructura anticuada del laborismo, le reconocía su hegemonía en la clase trabajadora y su papel en la política de izquierda (Davis, 2003, p. 40). Divididos entre su rol como meros intelectuales y políticos, la NIB surgió de 
una crisis que forzó a muchos intelectuales de izquierda a cuestionarse ideas preconcebidas sobre la naturaleza del proyecto socialista, el rol cambiante del capitalismo y el rol de la clase en este proceso.

También en las inmediaciones (y por un tiempo al interior) del LP, se formó el International Marxist Group (IMG) como una versión más radicalizada dentro de la izquierda británica. Luego de 1968 se apartaron del PL para adherirse a la IV Internacional. El IMG veía la polarización al interior del PL como un hecho positivo que podía devenir en una explosión de la colectividad, que liberase al partido de los obstáculos que le impedían aspirar al socialismo (Davis, 2009). Su objetivo central era lograr el derrocamiento del poder capitalista a través de la revolución para instaurar un gobierno basado en el control democrático directo de la gente.

El PCGB, por su parte, tuvo en los años setenta su momento de mayor influencia en el PL por sus vínculos con los sindicatos. Esto fue el resultado de una política trazada en 1947, cuando el secretario general, Harry Pollit, declaró la necesidad de encontrar una "vía británica al socialismo", señalando que "Inglaterra vería una transición pacífica al socialismo al interior del marco de la democracia parlamentaria sin lugar para Soviets o Dictadura del proletariado" (Callaghan, 2004, pp. 389-390). En este proceso, el PCGB reconoció la importancia del pL en el movimiento obrero y se impuso el papel de liberar al pL del ala derechista que obstaculizaba su camino al socialismo. No obstante, a pesar de la polarización y giro a la izquierda que se experimentó en Inglaterra en la década de los setenta, el PCGB decreció en importancia, principalmente por la acentuada merma en membresía. Esta se había iniciado en 1956, tanto por el discurso secreto de Khrushev denunciando las atrocidades de Stalin como por la invasión a Hungría, y había empeorado por la crisis del desempleo en los sectores claves para la militancia comunista. A la postre, fue la izquierda del PL quien capitalizó esta polarización (Callaghan, 2004).

Desde el Partido Conservador (PC), durante el gobierno de Edward Heath (1970-1974), habían surgido voces que proponían una posición más radical sobre la reducción del Estado y mayor preponderancia del mercado. Esto se combinaba con una campaña nacionalista en contra de la entrada a la Comunidad Económica Europea como de la inmigración. Ambos temas demostraron ser populares y potenciaron el ala autoritaria dentro del partido, polarizando a su vez el discurso político nacional. 


\section{CHILE EN LA POLÍTICA BRITÁNICA}

En este contexto, el caso chileno fue utilizado por ambos bandos para respaldar su posición. Por un lado, el mundo conservador esgrimió el ejemplo del manejo político y económico de Allende para asociarlo con el peligroso camino que el laborismo y los sindicatos estaban llevando a Inglaterra. En 1975, una editorial del periódico The Times miraba con preocupación cómo la izquierda laborista había ganado importantes batallas al interior del movimiento: "La izquierda en el Partido Laborista ahora es mucho más fuerte que en cualquier otro momento del período Bevanista." Para evitar que los socialistas se apoderasen del PL y pusieran en peligro las libertades, el editorialista hacía ver la necesidad de reformar el sistema electoral para evitar que el 15\% que tiene ideas socialistas terminara gobernando por sobre el $85 \%$ que no. En este punto, la columna hizo una comparación con Chile, señalando que fue el sistema electoral chileno el que dio el poder al Senador Allende, "ese héroe de nuestra propia izquierda, y resultó en la extinción de la libertad en Chile".

Tan cercanas y frecuentes eran las comparaciones con Chile, que se podría atribuir a ello la visión que el Foreign Office (conservador en su funcionamiento orgánico) tenía sobre los acontecimientos (Livingstone, 2018). En un oficio del embajador Secondé al Foreign Office, el primero se preguntaba extrañado por qué dilatar el reconocimiento del nuevo régimen militar en Chile: "Cualesquiera que hayan sido los excesos de los militares durante el golpe, la administración Allende estaba llevando al país a la ruina económica, el desorden social y el caos político". ${ }^{2}$ En otra carta del 28 de diciembre de 1973 dirigida al embajador Secondé, Hugh Carless, jefe del Departamento de América Latina, comentaba el buen trabajo del régimen en materia económica y se sorprendía por la "injusta atención" prestada internacionalmente al cambio de gobierno en Chile: "Chile ha sido elegido por la izquierda organizada como una nueva cruzada. El experimento marxista no ha sido enterrado ni olvidado: se mantiene vivo y se está pasando a la mitología del socialismo internacional. El bordado de la victoria democrática de Allende y la lucha de

${ }^{1}$ The Times, "Who are the masters next?", 1975. Judith Hart Coll. Labour Party Archives (en adelante LP/JH). Sección 4. Carpeta 10. Labour History Archive and Study Center (en adelante LHASC), Manchester.

${ }^{2}$ Confidential communication from R. L. Secondé to inmediate Fco Telegram Number 319, recibido el 19 de septiembre de 1973. Foreign and Commonwealth Office (FCO) 7/2412. The National Archives (en adelante TNA), UK. 
la Junta se ha convertido en una causa nueva y de moda en Europa, y también en algunos otros países."

Carless se lamentaba diciendo: "Parece que tendremos que vivir con el Movimiento de Solidaridad de Chile mientras la Junta gobierne Chile”.

Pronto se confirmaron los temores de Carless. A sólo ocho días del golpe militar, una delegación de parlamentarios del PL se reunió con el canciller Douglas-Home para solicitar información respecto a Chile y expresar formalmente la preocupación del PL. En dicha reunión, el futuro primer ministro James Callaghan "destacó que un gobierno de izquierda elegido democráticamente ha sido derrocado. Si se otorgara el reconocimiento, su partido presionaría al gobierno británico para que haga representaciones en nombre de los prisioneros del nuevo régimen." ${ }^{4}$

Todo lo anterior da cuenta del impacto que el caso chileno causó en el escenario político británico, donde fue visto por todos los actores como una fuente de lecciones a extraer. La lejanía geográfica de Chile contrastaba con lo cerca que el caso estaba para la política británica, cuyo desenlace se tornaba súbitamente en una posibilidad real para Inglaterra. Las percepciones sobre la ingobernabilidad del sistema político daban una sensación de punto sin retorno muy similar a lo acontecido en Chile. De hecho, para los conservadores, el fortalecimiento de un movimiento sindical que empujaba políticas socialistas conducía a la política y a los intereses económicos a un abismo irremontable.

\section{EL PL Y LA VÍA CHILENA AL SOCIALISMO}

El vínculo oficial entre la UP y el PL fue a través del Partido Radical (PR) chileno través de la Internacional Socialista (IISs). Parte del PR, y sus juventudes, habían experimentado un proceso de radicalización política hacia la izquierda, formando parte de la coalición de la up, lo que generó sendas divisiones al interior del radicalismo. El primer contacto oficial entre el PL y el PR, en este periodo, se dio en el marco de una reunión especial del Bureau de la IIss, realizada en Santiago en febrero de 1973. El objetivo de la reunión fue, en vista de las elecciones legislativas, apoyar al PR y, a través de ellos, a la UP y a Sal-

\footnotetext{
3 From H. Carless to R. Secondé. 28 de diciembre de 1973. FCO 7/2416. TNA, UK.

${ }^{4}$ Foreign and Commonwealth Office. 28 de diciembre de 1973. FCO 7/2418. TNA, UK.
} 
vador Allende. Durante dicha reunión, el PL emitió una declaración de apoyo al PR en su lucha por "establecer la justicia social basada en el respeto de los derechos humanos y los principios del socialismo democrático, y mejorar aún más el nivel de vida de los trabajadores". 5

El grupo Tribune (representantes de la izquierda del laborismo) apoyaba fuertemente las políticas de Allende. Eric Heffer, parlamentario y líder del grupo, escribió una columna en 1972 titulada "La vía pacífica de Chile hacia el socialismo", en donde expresaba la importancia del experimento para todos los socialistas del mundo, subrayando el carácter democrático de la UP. Aterrizando a la arena local, Heffer sostenía que de lograr el PL un programa tan radical como el de la UP, se verían enfrentados a los mismos problemas y, de fallar, sería un mal día para el socialismo en todos lados, conectando el destino de la UP con un proyecto mundial (Heffer, 1972, p. 215). En septiembre de 1973, el Comité Ejecutivo Nacional del pL declaraba que el derrocamiento del gobierno de Allende era un fuerte golpe para aquellos que buscaban establecer el socialismo por medios democráticos. Agregando que "la prisa indecente" del gobierno inglés por reconocer el régimen es un "símbolo de vergüenza para países como el nuestro con una tradición tan larga de asociación con la democracia chilena", por lo que se comprometían a rechazar cualquier tipo de ayuda, ya fuese económica o militar, que facilitase al régimen mantenerse en el poder. La declaración finalizaba señalando la necesidad de demostrar claramente "La solidaridad internacional de los socialistas democráticos con nuestros camaradas chilenos, quienes son víctimas de un ataque que es esencialmente un ataque a los ideales y aspiraciones de los socialistas democráticos en todo el mundo." ${ }^{\prime \prime}$

En las vinculaciones entre el PL y la UP, destaca de manera protagónica el papel desempeñado por Judith Hart. Primero desde su función como representante de su partido en los vínculos con Chile a través de la IIss y, luego, a través de su cargo desde 1974 como Ministro de Desarrollo de Ultramar, Hart pudo ejercer influencia directa al interior del gabinete británico para prestar apoyo a la causa democrática chilena. Específicamente sobre las lecciones del caso chileno para la política local, Hart escribía en septiembre de 1973 que los socialistas en el mundo entero estaban atentos al experimento chileno para

${ }^{5}$ News Release. Issued by the Labour Party Information Department. Signed by Ron Hayward, General Secretary. February 13, 1973. LP/JH. Sección 4. Del 1-3. LHASC, Manchester.

${ }^{6}$ LP/JH. Sección 4. Del 4-9. LHASC, Manchester. 
ver si era posible construir una sociedad socialista en un marco completamente democrático y sobre la base de cooperación entre socialistas y comunistas. Relacionando la problemática chilena con el contexto británico, Hart explicaba que las preguntas que habían ido emergiendo a propósito del golpe en Chile daban cuenta del nuevo dilema al que se enfrentan todos los demócratas socialistas; si era posible establecer el socialismo por medios democráticos o si siempre era necesaria la fuerza. Este dilema fue agudizado por las evaluaciones hechas por la derecha inglesa para quienes, según Hart, declararon que "El derrocamiento de gobiernos elegidos democráticamente, la sangrienta muerte y destrucción, y la represión violenta, son para ellos infinitamente preferibles a la tolerancia del socialismo. Es, por supuesto, una cuestión de relevancia directa para el socialismo europeo y británico." ${ }^{\text {Las respuestas de }}$ la derecha (tanto chilena como británica), según Hart, habrían incentivado una mayor cooperación entre las distintas vertientes de izquierda europea, intensificando el diálogo para maximizar las áreas de posibles acuerdos.

Vale destacar la duda que Hart explícitamente dejó abierta, sobre la real posibilidad de alcanzar el socialismo a través de medios democráticos y sin recurrir a la fuerza. En efecto, el caso chileno relevaba el debate de manera más aguda que ningún otro, tensionando las posibilidades reales de la estructura "democrática burguesa" en la consecución del socialismo. Era un contexto en el que la política británica estaba polarizada de manera general y el propio PL había visto cómo posiciones más radicales ganaban predominancia, especialmente desde los movimientos basales y sindicatos.

Tras las elecciones de 1974, el conservador Edward Heath fracasó en lograr acuerdo para formar una coalición con los liberales, dimitiendo como primer ministro. De esta manera, el PL formó un gobierno de minoría. Harold Wilson, líder del PL, convocó a nuevas elecciones para octubre del mismo año, obteniendo una estrecha mayoría de tres asientos. Esto significaba que el PL sólo contaba con 39.2\% del voto nacional, pero aun así estaba por sobre el Partido Conservador (35.8\%). Con todo, la suma entre PL y los conservadores en la elección de octubre sumaba 54.9\% del electorado, representando un declive electoral de los principales partidos británicos (Leys, 1989). En esta circunstancia, el PL inauguró un gobierno que duraría hasta 1979.

${ }^{7}$ Socialist International, Comisco y siLO. Box 558. International Institute of Social History (en adelante IISH), Amsterdam. 
El cambio de política hacia la causa democrática chilena entre el gobierno de Heath y el de Wilson fue notoria. Con Hart como ministro de Desarrollo de Ultramar se redirigió toda la ayuda que Gran Bretaña había comprometido para Chile, hacia el apoyo a la comunidad chilena en el exilio. Para 1975, se habían destinado 250000 libras para el trabajo con chilenos en el Alto Comisionado de Naciones Unidas para los Refugiados. También se otorgaron 40000 libras a la Cruz Roja para ayudar a perseguidos políticos chilenos. De manera especial, se financió un programa de becas para que chilenos pudiesen estudiar en el Reino Unido a través de la World University Service. El gasto total en este ítem durante 1975 fue de 600000 libras, previendo que el año financiero 1976/1977 sería de 900000 libras. Además, se financiaron activamente el trabajo de otras organizaciones no gubernamentales como el Catholic Fund for Overseas Development, dedicadas a apoyar a la comunidad chilena exiliada en Gran Bretaña. ${ }^{8}$

En febrero de 1975, los ministros del gabinete decidieron no renegociar la deuda que Chile mantenía con el Reino Unido. James Callaghan, Foreign Secretary, señaló en un telegrama que mientras el régimen militar chileno mantuviese sus políticas actuales, los objetivos políticos principales de gobierno estarían orientadas a actuar con otros gobiernos para reinstalar el respeto por los derechos humanos en Chile, ofrecer refugio a los perseguidos chilenos y preservar los intereses materiales del país y mantener la base para restablecer los vínculos tradicionales de cooperación que han existido entre ambos países desde hace 150 años. ${ }^{9}$ Los últimos dos puntos generaron controversia al interior del gabinete, pues se oponían a los representantes de la izquierda del laborismo, que abogaban por una línea más dura con respecto al régimen chileno. La división en el gabinete, generada por mantener una política más dura hacia el régimen militar chileno, sólo era una expresión más de las divisiones que determinaron el destino del gobierno laborista (Benn, 1989, p. 127).

A principio de los años ochenta, el connotado miembro del PL, Tony Benn, reflexionaba sobre el caso chileno en un contexto de fuerte repliegue de la izquierda británica y del ascenso de Thatcher en Gran Bretaña, en lo que denominó el "Dilema de Allende", en donde cuestionaba el éxito real de la

\footnotetext{
${ }^{8}$ Brief for Minister for Overseas Development: Cabinet defense and oversea policy committee, 19 de septiembre de 1975. FCO 7/2796. TNA, UK.

9 James Callaghan, FCO Telegram No. 406, 26 de noviembre de 1974. FCO 7/2796. TNA, UK.
} 
implementación de un programa socialista considerando la reacción que los intereses financieros liderados por Estados Unidos podrían tener frente a un gobierno laborista con un programa socialista (Benn, 1981-1982, p. 9).

\section{EL PARTIDO COMUNISTA DE GRAN BRETAÑA Y EL GOLPE EN CHILE}

La visión del golpe por parte del PCGB estuvo representada por Jack Woddis, líder del Departamento Internacional del partido. En una columna titulada "Mitin para apoyar la democracia chilena", Woddis hacía un llamado a todos los demócratas ingleses a exigir la liberación de los prisioneros y detener la represión. Con ello, se desmarcaba de la lógica izquierda y derecha para el caso chileno, ampliándolo a una confrontación que interpelaba a los demócratas en términos generales. ${ }^{10}$ Esta línea era la reforzada por Moscú, desde donde se impulsó la creación de amplios frentes antifascistas para dar cara internacionalmente a la campaña en contra del régimen de Pinochet. El sentido de esta política era la evocación de un pasado europeo asociado a los frentes populares que buscaba revitalizar el papel del comunismo como principal opositor a la emergencia de un percibido fascismo universal, representado por Pinochet en el caso chileno, a la vez que reivindicaba un rol de defensa de los derechos humanos revitalizando una deslegitimada imagen internacional soviética. El poder de la solidaridad con Chile, y la posibilidad del campo soviético y sus filiales, de representarse como los principales defensores de las víctimas de la represión, facilitaban la cooperación entre este y occidente bajo el amplio rótulo de la defensa de los derechos humanos (Christiaens, 2018). Mientras el vínculo entre el PCGB con Moscú se mantuvo, en casos como el Partido Comunista Italiano, se utilizó el caso chileno para construir distancias con el campo soviético, dirigiendo importantes desplazamientos doctrinarios hacia lo que se conoció como el Eurocomunismo (Santoni, 2011).

Al igual que el PL, Woddis utilizó el caso chileno para extraer lecciones aplicables a la realidad británica y enfatizar lo acertado del programa del partido: "La vía británica al socialismo". La primera lección era la necesidad de atraer a la gran mayoría de los trabajadores a la causa del socialismo: "millo-

\footnotetext{
${ }^{10}$ Rally to the support of Chilean democracy by Jack Woddis. LP/JH. Sección 4 . Del 4 al 9. LHASC, Manchester
} 
nes votan Labour, pero aún no comprenden la necesidad del socialismo, mucho menos qué se debe hacer para lograrlo". Segundo, se debía atraer y liderar otras secciones del pueblo que estaban siendo explotadas por los grandes monopolios. La conformación de una "alianza amplia democrática" permitiría tomar los pasos necesarios para la lucha parlamentaria y extraparlamentaria para romper el poder político y económico de los monopolios. Asimismo, era necesario hacer cambios democráticos al interior del Estado, especialmente del Ejército, para reducir la posibilidad de que la clase gobernante lo usase en contra de un gobierno de izquierda.

En otro documento del PCGB se estableció la relación directa con Chile al sostener que en Gran Bretaña se estaba usando la misma táctica que en Chile: una violencia de derecha orientada a crear caos y, por tanto, entregar una excusa para el golpe militar. Es la conclusión a la que llegó el PCGB tras el "apresurado reconocimiento de la Junta" por parte del gobierno Tory, la que demostró el desdén de las clases altas frente al proceso democrático y su disposición a utilizar la fuerza en contra del pueblo británico cuando este elija un gobierno dispuesto a realizar un ataque al poder de los grandes monopolios. ${ }^{11}$

Finalmente, y en una línea similar a las conclusiones de Hart, el PCGB enfatizó la necesidad de construir "amplias alianzas democráticas" para defender los derechos de los trabajadores, identificando un potente movimiento hacia la izquierda en el último tiempo. "El asesino golpe de estado en Chile ha despertado la ira y los profundos sentimientos de solidaridad internacional del movimiento laborista y sindical británico. Rara vez el movimiento ha estado tan unido". ${ }^{12}$

\section{VISIÓN DEL GOLPE CHILENO DESDE LA NUEVA IZQUIERDA (NIB) Y EL INTERNATIONAL MARXIST GROUP (IMG)}

Como ya se mencionó, los radicales europeos (en donde la NiB y grupos como el IMG se encontraban), culparon a los excesivos acuerdos entre Estados Uni-

${ }^{11}$ Communist Party of Great Britain, "Chile. Solidarity with the Popular Unity", LP/JH. Sección 4. Del 4 al 9. P 20. LHAsc, Manchester

${ }^{12}$ Communist Party of Great Britain, "Chile. Solidarity with the Popular Unity", LP/JH. Sección 4. Del 4 al 9. P 20, p. 23. LHAsc, Manchester 
dos y la URSS en el marco de la dètente por hechos como los ocurridos en Chile. Asociaron el fracaso del "reformismo burgués" de Allende con el imperialismo soviético y sus políticas estratégicas en el tercer mundo. Además, enfatizaron las similitudes entre la interferencia de multinacionales como la ITT en Portugal y Chile, denunciando el uso que Occidente hacía del eslogan anticomunista para legitimar su involucramiento. La lección extraída para esta línea era que la alianza entre comunistas y socialistas -altamente incentivada por el establishment de izquierda europea-, era una falsa estrategia para la revolución, puesto que sólo serviría a los intereses del capitalismo (Christiaens, 2018, pp. 418 y 430). La asociación del régimen de Pinochet, con las violaciones a los derechos humanos en el campo soviético, unificaron tanto a grupos como el IMG como a otros intelectuales de la NIB en un rechazo tanto al reformismo como a la dètente entre Este y Occidente.

En sus esfuerzos por abordar temas como la correcta estrategia para alcanzar el socialismo, junto a su marcado internacionalismo, algunos de los intelectuales de la NIB acudieron a influencias teóricas externas para dar sentido a su proyecto. En este marco, el caso de Chile se enarboló prontamente como modelo (o antimodelo). El mismo año de 1973, Ralph Miliband, quien fundó una de las revistas fundamentales del movimiento, The Socialist Register, reflexionaba sobre el golpe en Chile, señalando que no había nada novedoso en como reaccionaron quienes buscaban resguardar sus privilegios, pero sí habían impuesto difíciles preguntas para las personas de izquierda sobre la "estrategia" apropiada en los regímenes occidentales para la transición al socialismo. La lección sobre la estrategia en Chile se enlazaba con la cuestión del Estado y el ejercicio del poder. Un gobierno dispuesto a ejecutar cambios reales debe orientarse a implementar reformas innovadoras tendentes a la democratización del Estado. Esto puede evitar la confrontación o, en su defecto, minimizar sus efectos. La organización de redes de poder paralelas que complementen el poder del Estado y faciliten una estructura para la movilización de las masas. Miliband finalizaba estableciendo que la lección definitiva del caso de Chile no tiene relación con el uso de más o menos violencia en la persecución de un fin revolucionario, sino que, en último término, lo que realmente importa es constatar hasta qué punto los responsables de la dirección de esa lucha son capaces y están dispuestos a generar y alentar eficazmente su aplicación, es decir, fomentar la movilización organizada de las fuerzas populares (Miliband, 1973, p. 473). 
Tariq Ali, representante del ala radical de la NIB, escribió el documento "Lecciones del golpe". ${ }^{13}$ En este culpó a la up y específicamente al Partido Comunista de Chile (PCCh) por no preparar a la clase trabajadora para un eventual enfrentamiento con las instituciones de la burguesía. Ali señalaba que, por un lado, el golpe era un escenario previsible frente al cual la up no se supo preparar y, por otro, el PCch había sido reformista y colaboracionista, aliándose con partidos burgueses y defendiendo el camino democrático-burgués. En este sentido, Ali señaló que fue el Movimiento de Izquierda Revolucionaria (MIR), un grupo de ultraizquierda que defendía la vía revolucionaria para alcanzar la meta socialista, el único grupo político que hizo algo concreto por generar la revolución. ${ }^{14}$

Para Ali el golpe en Chile era una reafirmación de las visiones esenciales desde el marxismo-leninismo sobre el Estado y sus aparatos. Estas podían ser estudiadas desde la polémica entre Lenin y Kautsky, en donde Lenin sostenía la absoluta necesidad de destruir el aparato estatal burgués para pavimentar el poder de la clase trabajadora. ${ }^{15}$ Por ello, Ali entendía que no había mayor novedad en las lecciones que se extraen del golpe en Chile. Con respecto a las acciones de solidaridad posteriores al golpe, Ali criticaba el llamado del PCGB a "Apoyar la democracia chilena", denunciándolo como engañoso. El llamado no debía ser restablecer una democracia "burguesa", puesto que el contexto general por el que se luchaba era el socialismo. ${ }^{16}$

Asimismo, Gerry Hedley, importante representante del trotskismo en Inglaterra y fundador del Comité Internacional de la Cuarta Internacional, resaltaba que con el caso chileno se perfilaba el verdadero debate entre dos estrategias: la vía pacífica o la vía revolucionaria. El fracaso de la vía reformista de la UP era interpretado como un llamado a todos los revolucionarios del mundo "a denunciar clara y explícitamente la colaboración de clase del comunismo chileno y, al mismo tiempo, construir solidaridad y ofrecer consejo concreto para los revolucionarios en Chile". ${ }^{17}$

En línea con lo sostenido por Hedley, Ali (1977) señalaba que la solidaridad debe llevarse a la clase trabajadora y no sólo trabajar en generar resoluciones condenatorias. Se debía acentuar la relevancia de Chile para la lucha de la

13 Ali (1977). IISG Bro 431/8. IISH, Amsterdam.

${ }^{14}$ Ali (1977, p. 19). IISG Bro 431/8. IISH, Amsterdam.

${ }_{15}$ Ali (1977, p. 22). IISG Bro 431/8. IISH, Amsterdam.

${ }^{16}$ Ali (1977, p. 23). IISG Bro 431/8. IISH, Amsterdam.

${ }^{17}$ Hedley (1977, p. 48). IISG Bro 431/8. IISH, Amsterdam. 
clase trabajadora, tanto en Inglaterra como en el resto de Europa occidental: "Chile puede ser una tierra lejana, pero lo que pasó allá, ha tenido un impacto profundo en las secciones avanzadas del movimiento de la clase trabajadora en toda Europa" (p. 23). Para el caso británico, Ali (1977, p. 23) sostuvo que no sólo era un momento propicio en el contexto político inglés para reactivar la movilización de la lucha de la clase trabajadora, sino que era vital. Lo anterior debido a que el ejército británico, al igual que su par chileno, declaraba ser neutral, apolítico y profesional, pero una atenta mirada a la intervención en Irlanda del Norte y el trabajo del Brigadier Kitson, demostraba lo contrario.

\section{EL FRENTE UNIDO DE LA SOLIDARIDAD CON CHILE}

A pesar de las diferentes lecturas que el golpe de Estado en Chile, y el consecuente régimen militar, despertaron en las distintas versiones de la izquierda británica, todas vieron la necesidad de prestar apoyo a la causa chilena a través de campañas de solidaridad. Desde ahí, dejaron las diferencias de apreciación políticas que marcaban las distintas evaluaciones del gobierno de Allende y acordaron formas de denuncia y activismo político en contra del régimen militar. Asimismo, la participación en la campaña de solidaridad permitió la construcción de un puente revolucionario con todas las campañas de solidaridad con la causa chilena que proliferaron en Europa y el resto del mundo, y por extensión, con una comunidad revolucionaria imaginada que conectaba activistas europeos con revolucionarios del tercer mundo.

La unificación en torno a las campañas de solidaridad desde una dividida izquierda se facilitó además pues la campaña por Chile marcó un desplazamiento de un marxismo internacional y revolucionario a un ideario liberal basado en la defensa de los derechos humanos y la democracia (Gildea, Mark y Pas, 2011). Antes de 1973, las organizaciones de derechos humanos o no existían o eran muy pequeñas en su alcance. Como dice Patrick William Kelly (2013), "Chile, más que cualquier otro país, rediseñó el terreno del activismo en Derechos Humanos, especialmente en el plano transnacional" (p. 166). En concreto, el golpe en Chile, y especialmente el activismo de las campañas de solidaridad, alteró los entendimientos existentes en derecho internacional y soberanía estatal, pues las violaciones de derechos humanos ejercidas por el régimen de Pinochet dejaron de ser un tema de jurisdicción doméstica y fueron consideradas de responsabilidad internacional. Al respecto, Samuel 
Moyn sitúa al activismo por los derechos humanos como "la última utopía", tras las derrotas del activismo derivado del año 1968, permitiendo el encuentro de distintas sensibilidades de izquierda tras la narrativa de las campañas de solidaridad por Chile (Moyn, 2012).

Con el advenimiento en 1974 del PL en la dirección del gobierno, los grupos británicos de solidaridad con la causa democrática chilena proliferaron. Desde el gobierno se financiaron diversas organizaciones orientadas a apoyar a la comunidad chilena en el exilio británico. Muchas de estas organizaciones eran apartidistas y tenían como denominador común la denuncia de la violación de los derechos humanos perpetrados por el régimen militar chileno. Entre ellas, cabe destacar a "Academics for Chile" y al "Joint Working Group for Chilean Refugee” (Bayle, 2012).

Desde un ámbito político de izquierda, destaca la Chilean Solidarity Campaign (CSC), fundada por el PCGB, el PL y los sindicatos británicos. La csc fue una plataforma que, desde sus inicios, buscó ser un espacio lo más amplio posible para evitar fracturas que impactaran negativamente su trabajo (Bayle, 2010). Mike Gatehouse, principal secretario de la asociación, afirmaba la importancia de mantener un "un conglomerado de izquierda amplio [...] porque, en todas partes en Europa, las campañas de solidaridad se separaron y dividieron muy al inicio, debido a que los diversos grupos trotskistas tomaron el ejemplo de Chile como el principal ejemplo del fracaso del comunismo" (Jones, 2014, p. 32). De ahí que, al poco tiempo de su fundación, se incluyó en el directorio de la csc al IMG y al Socialists Workers Party, los dos grupos trotskistas más grandes en Inglaterra al momento del golpe. Esto reviste una particularidad del caso inglés en comparación con Francia o Italia en donde la interacción entre estas dos ramas de la izquierda, subrayando sus divergentes evaluaciones del caso chileno, se hacía especialmente difícil. En Inglaterra, la inclusión de los grupos trotskistas al directorio de la csc en la toma de decisión referente a la dirección de la campaña, además de mantener el frente de izquierda amplio, tuvo como segundo objetivo controlar las críticas de estos, tanto a las actividades de la csc como a la política de la UP (Jones, 2014). Como muestran los reportes de las reuniones anuales, las resoluciones propuestas por las diversas agrupaciones para el informe final eran cuidadosamente analizadas y su contenido final era sometido a voto por el consejo directivo. Esto permitía reconocer y minimizar las diferencias de enfoques para poder mantenerse como parte de la organización. Como ejemplo, la propuesta de resolución del PL, aprobada por 70 votos a favor y 0 
en contra, establecía que los principales objetivos de la csc debían ser aislar a la Junta y proveer de solidaridad concreta a todas las fuerzas de oposición al régimen. Estos objetivos, insistía la resolución, debían ser aprobados por todas las agrupaciones afines a la campaña para la "máxima eficiencia de una campaña unificada". ${ }^{18}$

Según el secretario de la csc, esta amplitud permitió apuntar hacia la unidad. ${ }^{19}$ En las conclusiones del secretario para la reunión anual de 1976 de la csc, se justificaban las acciones de solidaridad con Chile a raíz de las violaciones a los derechos humanos del régimen de Pinochet, ordenando de este modo el discurso que permitía unificar a una amplia gama de individuos y colectividades. ${ }^{20}$ En el mismo reporte se contabilizaban 19 sindicatos nacionales adheridos y 5800000 la membresía conjunta. Con la csc, la izquierda británica implementó las lecciones aprendidas de las separaciones desastrosas del movimiento de solidaridad por Vietnam y de la experiencia de la solidaridad francesa con Chile, en donde las diferencias políticas fracturaron la actividad colectiva de la solidaridad (Jones, 2014, p. 33).

En octubre de 1976, un editorial de Chile Fights (revista editada por la Csc) señalaba que "la causa por Chile ha alcanzado virtualmente todo los sectores del Labour y el movimiento progresista de Inglaterra" reconociendo que "el movimiento sindical británico ha llegado a ver la lucha chilena como una parte integrante de la suya propia" y que las amenazas que buscaron eliminar a la clase trabajadora en Chile "han sido reconocidas por los trabajadores británicos como una amenaza para los trabajadores de todas partes”. Prueba de lo anterior es que la marcha en protesta del golpe de Estado en Chile reunió a 10000 personas que caminaron desde Hyde Park a Trafalguar Square, representando "la mayor presencia de manifestantes desde las marchas por la ley de las relaciones industriales". ${ }^{21}$

La participación de los distintos actores de la izquierda británica en la campaña de solidaridad les permitió, por un lado, "publicitar eventos en Chi-

18 Annual General Meeting, December 14, 1974, Islington, p. 7. Chilean Solidarity Campaign Archives, csc/2/1-8. LHASc, Manchester.

19 Entrevista a Mike Gatehouse, realizada por Mariana Perry. 28 de agosto de 2018.

${ }^{20}$ Secretary's report. Annual General Meeting, London, February 7, 1976. Chilean Solidarity Campaign Archives, csc/2/1-8. LHAsc, Manchester.

${ }_{21}$ "Three years on", Chile Fights, núm. 21. Magazine of the Chilean Solidarity Campaign, septiembre-octubre de 1976. Chilean Solidarity Campaign Archives, csc/7/1-9. LHAsC, Manchester. 
le, convencer a nuestro gobierno de no dar ayuda o cualquier tipo de asistencia a la Junta Militar [...] desincentivar todas las formas de intercambio comercial o contacto con Chile con el fin de aislar a la Junta" y, por otro, "trabajar en conjunto con el movimiento en otros países para una efectiva solidaridad transnacional con el pueblo de Chile". ${ }^{22}$ Esto les permitió formar parte de una comunidad revolucionaria que se había movilizado por la defensa de los derechos humanos en todo el mundo. Al respecto, Chile Fights finalizaba indicando que "el movimiento británico de los trabajadores sabe que la lucha por el pueblo chileno es parte esencial de la lucha internacional por el socialismo". ${ }^{23}$

\section{CONCLUSIONES}

La experiencia chilena, lejana geográficamente, pero cercanas políticamente, fue utilizada por las distintas vertientes de la izquierda británica para extraer lecciones aplicables a su propia realidad. A propósito del fracaso de la UP y el régimen que se instaló, se debatieron temáticas locales que apremiaba a la izquierda del momento. El golpe en Chile se usó desde los partidos tradicionales (como el Laborista y el Comunista) para apelar a la unidad del movimiento obrero en contra de la derecha británica y los grandes monopolios. Por su parte, los grupos pertenecientes a la nueva izquierda británica y sus expresiones más radicales usaron el golpe para confirmar sus apreciaciones sobre la democracia burguesa y las diferencias con los partidos de la vieja izquierda europea.

Sin embargo, más allá de las diferencias que dividieron a la izquierda británica, fue la acción de la solidaridad con Chile una de las pocas instancias que permitieron el trabajo en conjunto y que facilitó la conexión con una comunidad revolucionaria ampliada. La solidaridad con Chile permitió la identificación de un activismo transnacional reunido en torno a la defensa de los derechos humanos difícilmente cuestionable, lo que facilitaba la acción colectiva tanto con actores locales como con actores globales. Este activismo transnacional posibilitaba reflexiones sobre la política local en la medida en

${ }^{22}$ Chile Solidarity Campaign Trade Union Conference. Delegate's briefing. No1: What is the CsC? Brief History, 1975, csc/11/2, p. 1. Chilean Solidarity Campaign Archives. LHASC, Manchester.

${ }_{23}$ "Three years on", Chile Fights, núm. 21. Magazine of the Chilean Solidarity Campaign, septiembre-octubre de 1976. Chilean Solidarity Campaign Archives, csc/7/1-9. LHASC, Manchester. 
que activismo y reflexión política eran entendidos como productos de un mismo movimiento global por el socialismo y la democracia. La actividad transnacional por la causa chilena permitía canalizar voluntades que habían visto con decepción el curso de la política soviética, por un lado, y un resurgimiento del espíritu colectivo a favor de un futuro socialista y democrático, por otro. Las lecciones particulares que cada agrupación había interpretado no impidieron que la potencia del movimiento de la solidaridad por la causa chilena moldeara los contornos del debate en la izquierda occidental, el que se ordenó tras el eje de los derechos humanos.

Esta adhesión por parte de un amplio arco de la izquierda inglesa (y europea) en torno a la defensa de los derechos humanos, en el caso chileno, y las potencialidades de su lectura en las temáticas locales, permiten redefinir el rol de casos del "Tercer Mundo" en la lógica de la guerra fría. Al interpelar y movilizar a tantos y tan diversos actores, el fin de la Unidad Popular y la consecuente instalación del régimen militar, desafió la unidireccionalidad norte-sur y reforzaron la idea de que eventos del Cono Sur fueron claves en moldear tanto la política de izquierda como el activismo transnacional de la generación que procedió a 1968, invitando a repensar los contornos de la guerra fría.

\section{LISTA DE REFERENCIAS}

Ali, T. (1977). Lessons of the Coup. En Chile: Lessons of the Coup. Which way to workers power? (pp. 1-23). International Marxist Group Pamphlet (Red Pamphlet, 7).

Angell, A. (1996). International support for the chilean opposition, 1973-1989: political parties and the role of exiles. En L. Whitehead, The international dimensions of democratization. Europe and the Americas (pp. 175-200). Nueva York: Oxford University Press.

Angell, A. (2013). Las dimensiones internacionales del golpe de Estado chileno. Política. Revista de Ciencia Política, 51(2), 57-78. DoI: https://doi. org/10.5354/0716-1077.2013.30156

Bayle, P. (2010). La diáspora de una población calificada: el exilio académico chileno en el Reino Unido. (Tesis de doctorado), Universidad Nacional de Cuyo-Facultad de Ciencias Políticas y Sociales, Mendoza, Argentina.

Bayle, P. (2012). Los rubios. The British commitment to the victims of the Chilean military dictatorship (1973-1990). Sociedad Hoy, 22, 77-93. 
Benn, T. (noviembre, 1981-enero, 1982). Se habla de la libertad en Polonia, pero se oprime en El Salvador. Entrevista por Raimundo Elgueta y Fernando Ruz. Convergencia, 5-6, 3-10.

Benn, T. (1989). Against the tide. Diaries 1973-76. Londres, U.A: Hutchinson.

Bracke, M. (2014). 1968. En S. Smith (ed.), The Oxford handbook of the history of communism (pp. 156-170). Nueva York: Oxford University Press.

Callaghan, J. (2004). Industrial militancy, 1945-79: The failure of the British road to socialism? Twentieth Century British History, 15(4), 388-409. Dor: https://doi. org/10.1093/tcbh/15.4.388

Camacho, F. (2013). El movimiento de solidaridad sueco con Chile durante la Guerra Fría. En T. Harmer y A. Riquelme (eds.), Chile y la guerra fría global (pp. 225-255). Santiago de Chile: RIL Editores.

Christiaens, K. (2017). Europe at the crossroads of three worlds: alternative histories and connections of European solidarity with the third world, 1950s-80s. European Review of History: Revue Européenne d'Histoire, 24(6), 932-954. DoI: https://doi.org/ 10.1080/13507486.2017.1345867

Christiaens, K. (2018). European reconfigurations of transnational activism: Solidarity and human rights campaigns on behalf of Chile during the 1970s and 1980s. International Review of Social History, 63(3), 413-448. DoI: https://doi.org/10.1017/ S0020859018000330

Christiaens, K., Rodríguez García, M. y Goddeeris, I. (2014). A global perspective on the European mobilization for Chile (1970s-1980s). En K. Christiaens, M. Rodríguez García e I. Goddeeris (eds.), European solidarity with Chile 1970s-1980s (pp. 7-46). Frankfurt: Peter Lang Editions.

Davis, M. (2003). "Laborism” and the new left. En J. Callaghan, S. Fielding y S. Ludlam (eds.), Interpreting the labour party. Approaches to labour politics and history. Manchester: Manchester University Press.

Davis, M. (2009). The origins of the British new left. En M. Klimke y J. Scharloth (eds.), 1968 in Europe: A history of protest and activism, 1956-1977 (pp. 45-56). Nueva York: Palgrave Macmillan.

Eley, G. (2002). Forging democracy. The history of the left in Europe, 1850-2000. Nueva York: Oxford Unviersity Press.

Gildea, R., Mark, J., y Pas, N. (2011). European radicals and the 'third world'. Cultural and Social History, 8(4), 449-472. DoI: https://doi.org/10.2752/14780041 1X13105523597733 
Green, J. (2003). Clergy, exiles and academics: Opposition to the Brazilian military dictatorship in the United States, 1969-1974. Latin American Politics and Society, 45(1), 87-117. DoI: https://doi.org/10.1111/j.1548-2456.2003.tb00233.x

Hatzky, C., y Stites Mor, J. (2014). Latin American Transnational Solidarities: Contexts and critical research paradigms. Journal of Iberian and Latin American, 20(2), 127-140. DOI: https://doi.org/10.1080/13260219.2014.939121

Hedley, G. (1977). Chile since the coup. En Chile. Lessons of the Coup. Which way to workers Power? Londres, International Marxist Group Pamphlet.

Heffer, E. (mayo, 1972). Chile's peaceful road to socialism. Labour Monthly, 211-215.

Jones, A. (2014). No truck with the Chilean Junta! Trade Union Internationalism, Australia and Britain, 1973-1980. Canberra: The Australian National University.

Kelly, P. W. (2013). The 1973 Chilean coup and the origins of transnational human rights activism. Journal of Global History, 8(1), 165-186. DoI: https://doi.org/10.1017/ S1740022813000090

Leys, C. (1989). Politics in Britain. From labourism to Thatcherism. Londres: Verso.

Livingstone, G. (2018). Britain and the dictatorships of Argentina and Chile, 1973-82. Londres: Palgrave Macmillan.

Livingstone, G. (2019). British campaigns for solidarity with Argentina and Chile. Bulletin of Latin American Research, 1-15. DoI: https://doi.org/10.1111/blar.13045

Marchesi, A. (2018). Latin America's radical left. Rebellion and cold war in the global 1960s. Nueva York: Cambridge University Press.

Miliband, R. (1973). The coup in Chile. Socialist Register, 10, 451-474.

Moyn, S. (2012). The last utopia: Human rights in history. Cambridge: Belknap Press of Harvard University Press.

Perry, M. (2016). "With a little help from my friends": The dutch solidarity movement and the Chilean struggle for democracy. European Review of Latin American and Caribbean Studies, 101, 75-96. DoI: http://doi.org/10.18352/erlacs.10114

Perry, M. (2017). Transferencia política en el exilio chileno en los Países Bajos, 19731989. El caso del Instituto para el Nuevo Chile. Historia (Santiago), 50(1), 175-207. DOI: http://dx.doi.org/10.4067/S0717-71942017000100007

Power, M. y Charlip, J. (2009). On Solidarity. Latin American Perspectives, 36(6:169), 3-9.

Sandbrook, D. (2013). Seasons in the sun. The battle for Britain, 1974-1979. Londres: Penguin Books.

Santoni, A. (2011). El comunismo italiano y la vía chilena. Los orígenes de un mito político. Santiago de Chile: RIL Editores.

Suri, J. (2003). Power and protest: global revolution and the rise of detente. Cambridge: Harvard University Press. 


\section{OTRAS FUENTES}

Archivos

IISH International Institute of Social History, Amsterdam.

LHASC Labour History Archive and Study Center, Manchester.

TNA The National Archives, UK. 